\title{
Aplikasi metode ground penetrating radar untuk mitigasi dini bencana tanah longsor di kecamatan Sawoo kabupaten Ponorogo
}

\author{
Uswatun Hasanah, Sujito*, Nugroho Adi Pramono \\ Universitas Negeri Malang, Jl. Semarang No. 5 Malang, Jawa Timur, Indonesia \\ *Penulis korespondensi, Surel: sujito.fmipa@um.ac.id
}

Paper received: Paper received: 01-01-2022; revised: 15-01-2022; accepted: 31-01-2022

\begin{abstract}
Abstrak
Dusun Nglumpang, Desa Pangkal Kecamatan Sawoo Kabupaten Ponorogo memiliki kondisi topografi yang berlereng-lereng sehingga rawan terjadi longsor. Pada tanggal 24 Desember 2014 telah terjadi longsor yang menyebabkan salah satu rumah warga tertimbun oleh reruntuhan tanah. Akibat dari longsor tersebut, rumah rusak parah sehingga pemilik rumah terpaksa harus mengungsi di rumah warga lain. Penelitian telah dilakukan di Desa Pangkal, Kecamatan Sawoo, Kabupaten Ponorogo di sekitar lokasi longsor yang bertujuan untuk mengetahui sebaran zona lemah berdasarkan letak zona cavity. Data yang digunakan berupa data hasil rekaman Ground Penetrating Radar (GPR) pada tanggal 15 Maret 2015. Untuk menggambarkan sebaran zona lemah dalam penelitian ini menggunakan metode Ground Penetrating Radar (GPR) Future Series 2005 dengan software visualizer 3D. Hasil dari metode ini berupa rekaman data yang menggambarkan sebaran zona lemah di daerah penelitian, Lintasan 1 terletak pada line 10,11, dan 12 yang berada pada kedalaman masing-masing 9,35, 9,47, 9,53 meter dibawah permukaan tanah. lintasan 2 pada line 2, 7, dan 8 yang berada pada kedalaman masing-masing 15,84, 9,90, 11,07 meter dibawah permukaan tanah. sedangkan untuk lintasan 3 pada line 1 dan 2 yang berada pada kedalaman 11,70 dan 12,21 meter dibawah permukaan tanah. Hasil penelitian didapatkan kesimpulan bahwa di daerah penelitian keberadaan rongga (cavity) rata-rata berada pada kedalaman diatas 10 meter. Adanya zona cavity inilah yang dapat dikatakan sebagai zona lemah sebagai pemicu terjadinya longsor.
\end{abstract}

Kata kunci: GPR; Future Series 2005; Software visualizer 3D; zona cavity; zona lemah

\section{Pendahuluan}

Kecamatan Sawoo berada di bagian Timur Kabupaten Ponorogo. Daerah ini merupakan jalur penghubung antar kota Ponorogo-Trenggalek yang berlereng-lereng dan berbukit-bukit. Data Badan Penanggulangan Bencana Daerah (BPBD) Jatim menyebutkan, dari 38 kabupaten/kota, sebanyak 20 daerah masuk katagori rawan terjadi tanah longsor, kategori tinggi, sedang, maupun ringan. 20 daerah tersebut, yakni Pacitan, Kabupaten Blitar, Trenggalek, Ponorogo, Batu, Lumajang, Jombang, Kabupaten Malang, Kabupaten Probolinggo, Jember, Bojonegoro, Kabupaten Madiun, Kabupaten Mojokerto, Kabupaten Pasuruan, Nganjuk, Situbondo, Bondowoso, Tulungagung, Magetan, dan Kediri (BPBD Jatim, 2009).

Kabupaten Ponorogo pada 24 Desember 2014 (lensaindonesia.com). Sebuah rumah tertimbun oleh reruntuhan tanah akibat hujan yang turun terus-menerus dari sore hingga malam hari Tanah longsor sering terjadi pada daerah atau lereng yang sama seperti tanah longsor sebelumnya. Ini karena kondisi geologi yang menyebabkan kondisi cenderung konstan pada jangka waktu yang panjang (Graniczny, Marek \& Ridgway, John). Untuk itu diperlukan metode yang dapat memberikan informasi keadaan bawah permukaan atau memberikan informasi pemicu terjadinya tanah longsor sebagai upaya untuk mengurangi resiko bencana serta penyadaran dan peningkatan kemampuan menghadapi ancaman bencana. 
Metode yang digunakan dalam penelitian adalah GPR (Ground Penetrating Radar). (GPR) Ground Penetrating Radar merupakan salah satu metode geofisika yang dapat mengidentifikasi bawah permukaan tanah dengan prinsip mengirimkan pulsa gelombang radio frekuensi kedalam tanah dari antena pemancar yang terletak di permukaan. Metode ini dianggap sebagai metode yang paling prospektif, karena memiliki resolusi dan kecepatan ekuisisi data tinggi untuk menyelidiki berbagai masalah kebumian dikhususkan dalam eksplorasi dangkal dan tidak merusak (Arisona, 2009).

Struktur geologi bawah tanah memberikan nilai yang signifikan bagi studi dan aplikasi teknik. Secara khusus sangat penting untuk memahami status geologi misalnya air permukaan, rongga, kemiringan, pelapukan, dll. (Chih Lin, Ming, et al, 2013). Kondisi alam mampu memberikan dukungan yang sangat baik bagi kehidupan manusia. Alam memiliki sifat dinamis yang dapat memberikan sesuatu hal yang positif jika dibarengi dengan keserasian dalam pengelolaannya. Oleh karena itu diperlukan studi struktur bawah permukaan agar dapat memberikan pengetahuan sekaligus informasi tentang daerah rawan longsor.

\section{Tinjauan pustaka}

Kabupaten Ponorogo adalah salah satu kabupaten yang terletak di Propinsi Jawa Timur terletak di koordinat $111^{\circ} 17^{\prime}-111^{\circ} 52^{\prime} \mathrm{BT}$ dan $7^{\circ} 49^{\prime}-8^{\circ} 20^{\prime}$ LS dengan ketinggian antara 92 sampai dengan 2.563 meter di atas permukaan laut yang memiliki luas wilayah $1.305,70 \mathrm{~km} 2$ dengan jumlah penduduk 1.009.701 jiwa. Wilayah administrasi terdiri dari 21 Kecamatan, 26 Kelurahan, dan 279 Dusun (sumber: kemendagri). Lokasi daerah yang beresiko tanah longsor dikendalikan oleh dua faktor utama yaitu adanya lereng dengan struktur geologi yang tidak menguntungkan, dan tingkat curah hujan yang tinggi (Graniczny, Marek \& Ridgway, John).

Tanah longsor adalah perpindahan material pembentuk lereng berupa batuan, bahan rombakan, tanah, atau material campuran tersebut yang bergerak ke bawah atau keluar lereng (Highland, L \& Margo, 2004). Proses terjadinya tanah longsor ketika air yang meresap ke dalam tanah akan menambah bobot tanah. Jika air tersebut menembus sampai tanah kedap air yang berperan sebagai bidang gelincir, maka tanah menjadi licin dan tanah pelapukan di atasnya akan bergerak mengikuti lereng dan keluar lereng (Arianto dalam Sari, 2012).

Amblesan (subsidence) adalah gerakan ke bawah dipermukaan bumi dari suatu datum, sehingga elevasi muka tanahnya berkurang atau menjadi lebih rendah dari semula. Kebalikannya adalah pengangkatan (uplift) yang menghasilkan naiknya permukaan atau elevasi permukaan tanahnya bertambah (Sudarsono, U \& Sudjarwo, I.B, 2008). Amblesan dapat disebabkan antara lain ekstraksi cairan (seperti air tanah, minyak termasuk gas dan gheotermal), tambang bawah permukaan, proses pelarutan batuan-batuan seperti batu garam, gypsum, batu gamping, dolomit, kompaksi dan tektonik (Sudarsono, U \& Sudjarwo, I.B, 2008).

Radar (Radar Detection and Ranging) adalah suatu sistem pendeteksi obyek yang menggunakan gelombang elektromagnetik untuk identifikasi jarak (range), arah (direction) atau kecepatan (speed) baik obyek bergerak maupun diam. Sistem radar terdiri dari bagian transmitter dan receiver yang letaknya pada lokasi sama atau terpisah. Transmitter mengemisikan gelombang radio pada frekuensi tertentu. gelombang radio pada medium struktur lapisan bawah permukaan bumi selanjutnya akan dihamburkan, dipantulkan dan diteruskan sesuai dengan parameter-parameter permeabilitas magnet $(\boldsymbol{\mu})$, permitivitas $(\varepsilon)$ dan konduktivitas $(\sigma)$. 
Setelah menempuh jarak tertentu, amplitude gelombang akan mengalami peredaman atau atenuasi. Kecepatan gelombang elektromagnetik dalam beberapa medium tergantung pada kecepatan cahaya di udara ( $\mathrm{c}=300 \mathrm{~mm} / \mathrm{ns}$ ), konstanta dielektrik $\left(\varepsilon_{r}\right)$ dan permeabilitas magnetic relative ( $\boldsymbol{\mu}=1$ untuk material non magnetik) (Suptiyanto, E., 2007). Persamaan Maxwell dapat dipandang sebagai hubungan antara medan distribusi sumber(muatan atau arus) yang bersangkutan (Deniyatno, 2011). Persamaan gelombang elektromagnetik dalam medium non-konduktor akan mengakibatkan pergeseran medan listrik serta adanya medan magnet dalam medium. Nilai medan magnet dan medan listrik yang mengalami pergeseran dan pergerakan.

Metode Ground Penetrating Radar (GPR) merupakan suatu teknik yang digunakan untuk deteksi bawah permukaan. dalam penggunaanya, teknik ini dapat memberikan informasi struktur lapisan bawah permukaan, lokasi perubahan dari bangunan dan dapat memberikan petunjuk keberadaan saluran air. Dengan adanya informasi ini, peneliti dapat lebih tepat dalam menentukan target sasaran dalam sampling fisika (Muller, Wayne. 2009). Ground Penetrating Radar (GPR) memiliki cara kerja mengirim pulsa energi antara 10 sampai $1000 \mathrm{MHz}$ ke dalam tanah dari suatu antenna, kemudian merekam pemantulannya dalam waktu singkat. Jika suatu pulsa GPR atau gelombang elektromagnetik mengenai suatu lapisan atau obyek dengan konstanta dielektrik berbeda, pulsa akan dipantulkan ditangkap oleh antena penerima yang selanjutnya hasilnya akan direkam oleh GPR yang berupa gambar (image) (Oktafiani, F., et al).

GPR Tipe Future Series 2005 berbeda dengan GPR konvensional pada umumnya. Pada antena terdiri dari beberapa receiver dan satu transmitter yang berada di tengah-tengah antena sehingga outputnya berupa kontur yang menggambarkan penampang horizontal dari daerah penelitian. Jika obyek yang dikenai bersifat konduktif maka sinyal yang ditangkap semakin jelas. warna kuning mengartikan bahwa terdapat anomali mineral di daerah penelitian. Anomali lainnya ditunjukkan oleh warna biru tua, biru muda dan hijau. Warna biru tua memberikan informasi bahwa daerah tersebut adalah cavity area (zona kosong). Warna biru muda memberikan informasi wet area (zona basah). Sedangkan warna hijau memberikan informasi dry area (zona kering) (Bahri, A.S., et al, 2009).

\section{Metode}

Penelitian dilakukan pada tanggal 15-16 Maret 2015 di Dusun Nglumpang, Kelurahan Pangkal RT/RW 02/01, Kecamatan Sawoo, Kabupaten Ponorogo.

\subsection{Alat Penelitian}

2.1.1. Alat-alat yang digunakan dalam penelitian ini yaitu sebagai berikut.

2.1.2. Antenna Unit

2.1.3. Power Supply Unit $(9 \mathrm{~A} / \mathrm{h})$

2.1.4. Control Unit

2.1.5. Kabel Penghubung setiap unit

2.1.6. Sensor

2.1.7. Notebook PC \& Bluetooth

\subsection{Pengambilan Data Lapangan}

Prosedur pengambilan data lapangan yaitu sebagai berikut. 
2.2.1. Menentukan letak lintasan berada, menentukan jumlah lintasan, dan memperkirakan serta mengukur berapa panjang lintasan yang akan diamati.

2.2.2. Menyusun alat sesuai dengan prosedur yang benar.

2.2.3. Menghidupkan power supply.

2.2.4. Menentukan impuls pada GPR yang akan digunakan pengambilan data.

2.2.5. Menghubungkan alat GPR dengan notebook PC menggunakan bluetooth.

2.2.6. Menekan tombol ready pada GPR.

2.2.7. Melakukan pengambilan data dengan cara menjalankan sensor GPR diatas permukaan tanah.

2.2.8. Mengulangi langkah-langkah diatas pada lintasan selanjutnya.

\subsection{Pengolahan Data}

Pengolahan data dilakukan oleh software visualizer $3 D$ yang merupakan satu paket dengan dengan GPR Future Series 2005 yang menampilkan hasil akuisisi data secara langsung. Rangkaian alat GPR Future Series 2005 dikoneksikan dengan komputer dengan memanfaatkan teknologi bluetooth. Kemudian melakukan analisis data dengan menggunakan data yang berasal dari output software visualizer $3 D$.

\section{Hasil dan Pembahasan}

Hasil rekaman data GPR di Desa Pangkal, Kec. Sawoo, Kab. Ponorogo tanggal 15 Maret 2015 diinterpretasikan dalam bentuk penampang 2D lintasan 1, 2, 3.

Gambar 1. Lintasan 1

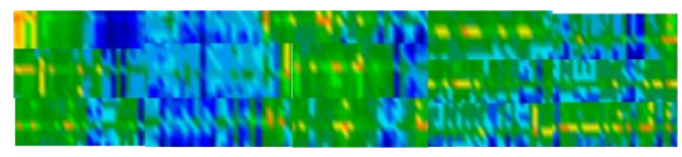

Gambar 2. Lintasan 2

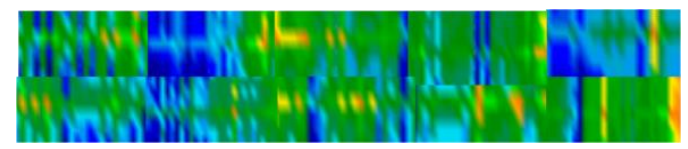

Gambar 3. Lintasan 3

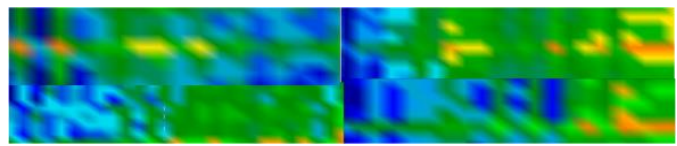

Pengukuran kedalaman dari beberapa line dari cavity dapat ditunjukkan dalam tabel berikut.

Tabel 1. List of Depth Lintasan 1

\begin{tabular}{lll}
\hline Line & Max Depth $(\mathrm{m})$ & Depth of Blue $(\mathrm{m})$ \\
\hline 1 & 14,08 & 14,08 \\
2 & 13,30 & 11,70 \\
3 & 13,37 & 11,57 \\
4 & 14,27 & 10,67 \\
5 & 13,03 & 11,83 \\
6 & 17,55 & 7,20 \\
7 & 13,77 & 13,77
\end{tabular}




$\begin{array}{lll}8 & 13,67 & 13,67 \\ 9 & 12,63 & 12,63 \\ 10 & 15,75 & 9,35 \\ 11 & 15,47 & 9,47 \\ 12 & 15,43 & 9,53 \\ 13 & 13,14 & 13,14 \\ 14 & 13,13 & 13,13 \\ 15 & 13,18 & 11,78\end{array}$

Tabel 2. List of Depth Lintasan 2

\begin{tabular}{lll}
\hline Line & Max Depth $(\mathrm{m})$ & Depth of Blue $(\mathrm{m})$ \\
\hline 1 & 15,14 & 15,14 \\
2 & 15,84 & 15,84 \\
3 & 13,25 & 13,25 \\
4 & 13,27 & 13,27 \\
5 & 13,61 & 13,61 \\
6 & 13,95 & 13,95 \\
7 & 15,01 & 9,90 \\
8 & 14,07 & 11,07 \\
9 & 13,35 & 11,65 \\
10 & 11,65 & 11,65 \\
\end{tabular}

Tabel 3. List of Depth Lintasan 3

\begin{tabular}{lll}
\hline Line & Max Depth $(\mathrm{m})$ & Depth of Blue $(\mathrm{m})$ \\
\hline 1 & 13,20 & 11,70 \\
2 & 12,71 & 12,21 \\
3 & 12,51 & 12,51 \\
4 & 14,74 & 10,34 \\
\hline
\end{tabular}

\section{Simpulan}

\subsection{Kesimpulan}

Sebaran zona lemah di Desa Pangkal, Kec. Sawoo, Kab. Ponorogo ditandai dengan adanya zona cavity pada tiap lintasan. Lintasan 1 terletak pada line 10,11, dan 12 yang berada pada kedalaman masing-masing 9,35, 9,47, 9,53 meter dibawah permukaan tanah. lintasan 2 pada line 2, 7, dan 8 yang berada pada kedalaman masing-masing 15,84, 9,90, 11,07 meter dibawah permukaan tanah. sedangkan untuk lintasan 3 pada line 1 dan 2 yang berada pada kedalaman 11,70 dan 12,21 meter dibawah permukaan tanah.

Sedangkan untuk mengetahui informasi stratigrafi daerah penelitian dapat dilakukan dengan melihat peta geologi daerah penelitian. Diketahui bahwa struktur bawah permukaan berupa endapan alluvium yaitu bahan gunung api, pasir, kerikil, lumpur, dan kerakal. Jenis batuan ini jika berada pada daerah yang berlereng-lereng akan mudah terjadi longsor.

\subsection{Saran}

Pada daerah penelitian, berdasarkan hasil rekaman GPR terdeteksi adanya zona kosong (cavity) yang menunjukkan zona lemah yang berarti bahwa daerah tersebut berpotensi terjadi 
longsor. Hal ini perlu mendapat perhatian dengan cara memberikan peringatan agar masyarakat sekitar daerah penelitian lebih waspada terutama penduduk yang berada di bawah daerah penelitian terhadap bahaya longsor. Apalagi ketika musim penghujan tiba, bahaya longsor yang tidak terduga dapat terjadi dan dapat mengancam kelangsungan hidup masyarakat setempat.

Bagi peneliti, sebaiknya sebelum melakukan penelitian banyak membaca literatur yang berkaitan dengan tema yang diteliti agar memperoleh wawasan yang luas tentang pokok masalah yang diajukan sebelum akhirnya penulis sendiri bisa menjawab hasil data yang diperoleh.

\section{Daftar Rujukan}

Arisona. (2009). Migrasi Data Georadar dengan Metode Pergeseran Fasa. Jurnal Aplikasi Fisika. Vol.5, No. 1.

Bahri, Ayi Syaeful et al, (2009). Penentuan Karakteristik Dinding Gua Seropan Gunungkidul dengan Metode Ground Penetrating Radar. Surabaya: Universitas Sebelas Maret.

Chih Lin, Ming, et al. (2013). GPR Applications in the Detection of Underground Drainage Culvert Research. Journal of Emerging Trends in Engineering and Applied Sciences (JETEAS) 4(4):572-575 (ISSN: 21417016).

Graniczny, Marek, et al. Slope Failure (Landslides) And Surface Displacement Geoindicators. Polish Geological Institute ST. Rakowiecka 4 - 00-975 Warszawa - Poland.

Kemendagri, (2011). Letak Geografis Kota Ponorogo, Retrieved Februari 20,205, from http://www.kemendagri.go.id

Muller, Wayne. (2009). Application of Ground Penetrating Radar to Road Pavement Rehabilitation. Institute of Public Works Engineering Australia Queensland state conference, 7 March 2009.

Oktafiani, F., Sulistyaningsih, S., \& Wijayanto, Y. N. (2010). Sistem Ground Penetrating Radar untuk Mendeteksi Benda-benda di Bawah Permukaan Tanah. INKOM Journal, 1(2), 53-57.

Sari, E. S. (2012). Identifikasi potensi gerakan tanah di Lereng Sukorejo Desa Sukorejo, Kevamatan KalidawerTulungagung dengan metode analisis struktur batuan berdasarkan sifat resistivitas hasil pengukuran flashres64 61-channel (Doctoral dissertation, Universitas Negeri Malang).

Sudarsono, U., \& Sudjarwo, I. B. (2008). Amblesan di daerah Porong, Kabupaten Sidoarjo, Jawa Timur. Indonesian Journal on Geoscience, 3(1), 1-9.

Supriyanto. (2007). Perambatan Gelombang Elektromagnetik. Tesis. Departemen Fisika-FMIPA: Universitas Indonesia. 